\title{
Techniques of intraoperative cerebral blood flow measurement
}

\author{
Jonathan A. Friedman, M.D., Robert E. Anderson, B.S., And Fredric B. Meyer, M.D. \\ Department of Neurological Surgery, Mayo Clinic, Rochester, Minnesota
}

\begin{abstract}
Understanding the physiological mechanisms of cerebral blood flow (CBF) is of great importance to neurosurgeons engaged in the management of patients with cerebrovascular disease. Over the past 50 years, techniques to measure $\mathrm{CBF}$ and mathematical methods to calculate $\mathrm{CBF}$ have evolved substantially. For the cerebrovascular surgeon, intraoperative CBF monitoring is an important adjunct in certain intra- and extracranial procedures. The authors review current techniques in use for the intraoperative measurement of $\mathrm{CBF}$.
\end{abstract}

\section{KEY WORDS - cerebral blood flow - intraoperative monitoring • xenon study • transcranial Doppler ultrasonography}

The brain uses aerobic metabolism exclusively for energy production. Accordingly, the brain is critically dependent on the nearly continuous delivery of oxygen and glucose to sustain cellular energy production. Resting CBF in the awake patient is approximately $50 \mathrm{ml} / 100 \mathrm{~g}$ brain tissue/min. ${ }^{26}$ As CBF decreases, neuronal dysfunction and injury occur. At levels of 16 to $18 \mathrm{ml} / 100 \mathrm{~g} / \mathrm{min}$, cortical electrical function fails, as evidenced by attenuation in EEG and SSEP recordings. At levels of approximately 10 $\mathrm{ml} / 100 \mathrm{~g} / \mathrm{min}$ or less, rapid changes in intracellular and extracellular ion concentrations occur, as well as the development of intracellular acidosis. Persistence of $\mathrm{CBF}$ at levels below this threshold of maintaining ionic balance will result in membrane disruption, irreversible neuronal injury, and cell death.

Intraoperative monitoring of $\mathrm{CBF}$, both qualitatively and quantitatively, has contributed to improved outcomes after cerebrovascular procedures. ${ }^{2}$ In patients undergoing CEA, the use of intraoperative CBF measurements has proven to be effective in reducing operative morbidity. ${ }^{4,5,43,44}$ Intraoperative CBF monitoring has also been a useful adjunct in the treatment of complex intracranial aneurysms and arteriovenous malformations, particularly when temporary or permanent vessel occlusion is undertaken. ${ }^{2,30}$ We review the current state-of-the-art techniques for the monitoring of $\mathrm{CBF}$.

Abbreviations used in this paper: $\mathrm{CA}=$ carotid artery; $\mathrm{CBF}=$ cerebral blood flow; $\mathrm{CEA}=$ carotid endarterectomy; $\mathrm{EEG}=$ electroencephalogram; SSEP = somatosensory evoked potential; $\mathrm{TCD}=$ transcranial Doppler; ${ }^{133} \mathrm{Xe}=$ Xenon-133.

\section{QUALITATIVE CBF MONITORING TECHNIQUES}

\section{Neurological Examination}

The neurological examination is a sensitive, qualitative technique used to assess the adequacy of CBF during cerebrovascular procedures. The primary limitation is that the patient must be awake during the procedure. For patients undergoing CEA, this generally poses no major difficulties. Using a cervical ganglion block, the procedure is performed with ongoing neurological and language-response examination. Because CEA in an awake patient obviates the need for EEG monitoring and allows the patient to be discharged within 24 hours, there is a clear benefit in cost. Furthermore, it is likely that cardiac complications are reduced when regional anesthesia is used compared with general anesthesia for CEA. ${ }^{34}$ Some patients, however, will not tolerate undergoing an awake procedure.

\section{Transcranial Doppler Ultrasonography}

The use of TCD ultrasonography has been advocated as a tool to measure CBF velocity in the ipsilateral middle cerebral artery during carotid endarterectomy. ${ }^{17,23,25,27,42}$ The technique is well established but, because of variations in normal vessel diameter and operative technique, TCD studies can provide only a relative index of CBF based on normal ranges. ${ }^{25}$ As equipment and surgical experience have evolved, the technique has been used more frequently in intraoperative monitoring. Recently, a very large study reported by Ackerstaff and colleagues ${ }^{1}$ 
demonstrated that TCD-depicted variables accurately predicted stroke during or immediately following CEA. Furthermore, TCD studies, with high sensitivity, can identify patients at risk for postendarterectomy hyperperfusion syndrome and hemorrhage. ${ }^{1,13}$ Whereas the technique has the advantage of being noninvasive, the cost effectiveness of TCD monitoring during CEA remains unknown.

\section{Electroencephalography and SSEP Monitoring}

Electroencephalography is an indirect, qualitative measurement of $\mathrm{CBF}$ in patients undergoing cerebrovascular surgery. It is a highly sensitive marker of CBF, as there is a strong correlation between alterations in the EEG and diminished $\mathrm{CBF}^{29,40}$ The technique has become commonplace for monitoring $\mathrm{CBF}$ in patients undergoing CEA. ${ }^{12,31,38,48}$ For intracranial procedures, surface EEG strips can be used. Techniques for intraoperative cerebral protection, such as barbiturate administration or hypothermia, may limit the sensitivity of EEG for the detection of cerebral ischemia, yet EEG is useful in titration of the protective effect when burst suppression is desired. ${ }^{3,37,39}$ Measurement of SSEPs is another neurophysiological monitoring technique currently used in some centers during extracranial vascular surgery. ${ }^{22}$ Of note, SSEP monitoring may be valuable when reconstructing the vertebral artery circulation, as SSEPs may be more sensitive in detecting brainstem ischemia than EEG.

\section{Intraoperative Angiography}

Particularly in the surgical treatment of giant or complex intracranial aneurysms, it is important to have the option of obtaining an intraoperative angiogram; this allows for the qualitative assessment of the presence and adequacy of $\mathrm{CBF}$ and the patency of specific cerebral blood vessels following aneurysm repair. ${ }^{5,33}$ Routine use of intraoperative angiography in aneurysm surgery has been reported more frequently of late. In a recent study, intraoperative angiography led to clip repositioning in $10 \%$ of 520 consecutive cases. ${ }^{45}$ Accordingly, in all cases in which intraoperative angiography may be required, the head should be fixed with a radiolucent headholder. It is important to position the patient high up on the operating room table so that the shoulders hang over the edge. This will facilitate adequate positioning of the image intensifier. Furthermore, it is advantageous to limit the use of selfretaining retractors, because the retractor bars will obscure good visualization on the intraoperative angiogram. If the cervical CA has been exposed, it can provide an easy route to perform intraoperative angiography through a direct CA puncture. Alternatively, the femoral artery can be cannulated for vascular access.

\section{QUANTITATIVE CBF MONITORINGTECHNIQUES}

\section{Xenon-133 Study}

The most widely used method of intraoperative $\mathrm{CBF}$ measurement, and the technique used at our institution, is the intraarterial injection of ${ }^{133} \mathrm{Xe}$ into the internal CA and the extracranial detection of the clearance curve deter- mined using highly collimated scintillation detectors (Fig. 1). Xenon-133 is a low-energy gamma emitter that diffuses freely through the brain and, thus, is an ideal agent for measurement of CBF.

Xenon-133 is a radionuclide that is chemically related to the element xenon, a nonradioactive gas that is chemically inert. The radionuclide has anesthetic properties at concentrations greater than $33 \%$. It has an unstable nucleus, continuously emitting beta, gamma, and x-ray photons. The emitted photons are of low energy and, as such, can be absorbed by $0.1 \mathrm{ml}$ of lead to reduce exposure by $90 \%$. The physical half-life of ${ }^{133} \mathrm{Xe}$ is 5.27 days. It is distributed as a $5 \%$ concentration mixed with $95 \% \mathrm{CO}_{2}$, which is then dissolved in $0.9 \%$ sodium chloride for injection. ${ }^{2}$ Xenon-133 freely passes through cell membranes, crosses the blood-brain barrier, and is not metabolized anywhere in the body. After injection into the internal CA, it is retained momentarily in brain tissue and is then released through normal venous outflow channels. Ninety percent of ${ }^{133} \mathrm{Xe}$ is expelled through the lungs on firstpass, thereby minimizing recirculation of the radionuclide through the cerebral vasculature. ${ }^{2}$

Appropriate safety measures must be taken to minimize radiation exposure to medical staff and patients. In handling ${ }^{133} \mathrm{Xe}$, care should be taken to avoid direct contact with the hands or any other part of the body. Our standard use involves $0.6 \mathrm{rad} / \mathrm{minute}$ of exposure time for the surgeon and less than $5-\mu \mathrm{rad} /$ minute exposure to surrounding personnel. The maximum permissible exposure, as set by the Nuclear Regulatory Commission, to the hands and body is 75 rads and 5 rads per year, respectively. Thus, the exposure encountered in typical use is well below safe limits. In patients, exposure varies by procedure. For a CEA, the estimated absorbed radiation dose in an average patient from a maximum total dose of $1.6 \mathrm{mCi}$ would be $0.5 \mathrm{mrad}$ to the lungs, $30 \mathrm{mrad}$ to the brain, and $0.9 \mathrm{mrad}$ to the rest of the body. Because of the potential risks, ${ }^{133} \mathrm{Xe}$ should generally be avoided in pregnant women.

It is important to obtain baseline measurements of ${ }^{133} \mathrm{Xe}$ for each patient intraoperatively. Accuracy of the instrumentation and measurement devices must also be verified. The main components of the ${ }^{133} \mathrm{Xe} \mathrm{CBF}$ measurement system are a scintillation detector, pulse-height amplifier, count-rate meter, power supplies, and a strip chart recorder (Fig. 1). The two types of scintillation detectors in use today are thallium-activated sodium iodide crystal (NaI[TL]), and CdTe. The NaI(TL) detector uses a scintillation crystal that converts the energy of the incoming photons into visible light, and it is coupled to a photomultiplier tube, which then converts these scintillations into electrical pulses. The crystal thickness is usually $6 \mathrm{~mm}$ to provide maximum counting efficacy, which is approximately 90 to $99 \%$ for ${ }^{133} \mathrm{Xe}$. The crystal is mounted behind a lead collimator that is $25 \mathrm{~mm}$ thick and has a tapered opening from $30 \mathrm{~mm}$ at the surface of the crystal to $22 \mathrm{~mm}$ at the front end. This detector assembly consisting of the collimator, crystal, photomultiplier tube, and preamplifier is mounted on a stand that can be moved up to the patient's head. The CdTe crystal is $16 \mathrm{~mm}$ in diameter by $2 \mathrm{~mm}$ thick and is mounted inside a lead collimator that is packaged in a metal cylinder. This unit is attached to the patient's head by means of a strap. The counting efficiency 


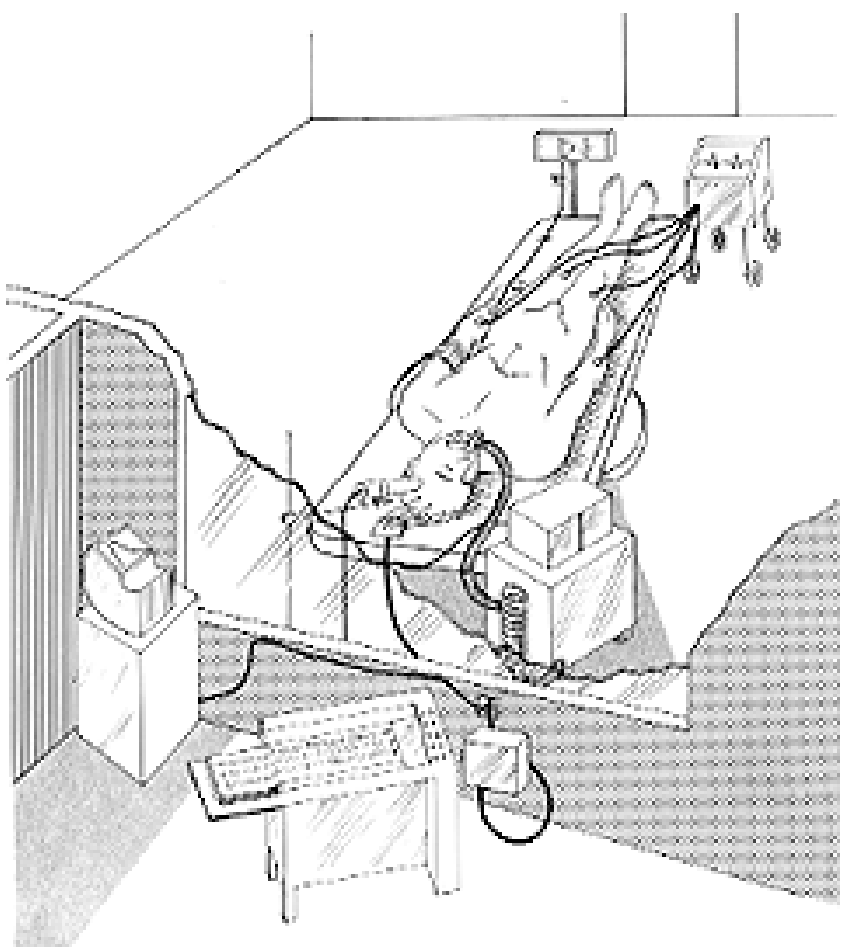

Fig. 1. Illustration showing the operating and control room layout for ${ }^{133} \mathrm{Xe} \mathrm{CBF}$ measurement and EEG monitoring. With permission from the Mayo Foundation.

of this unit with ${ }^{133} \mathrm{Xe}$ is $96 \%$. The detector is lighter weight and operates at a lower voltage than the NaI(TL) system, but it is more expensive.

Signal processing of the electrical pulses generated by the detector assembly requires a preamplifier, amplifier, pulse-height analyzer, and count-rate meter. The preamplifier and amplifier function to match the impedance level between the scintillation detector and the preamplifier and to amplify the low-voltage pulses from the preamplifier to a sufficient level to drive the pulse-height analyzer. The pulse-height analyzer is used to select only those pulses that coincide with the energy level of ${ }^{133} \mathrm{Xe}(81$ $\mathrm{keV}$ ) and discriminate against background noise and scattered radiation outside the selected energy range (75-200 $\mathrm{keV})$. The count-rate meter is used to determine the average number of counts per unit time, and the counts are recorded on a strip chart recorder.

Ultimately, the measurements obtained by the scintillation detectors and processed as just described yield clearance curves representing the washout of ${ }^{133} \mathrm{Xe}$ (Fig. $2)$. These clearance curves can be analyzed by one of several methods for curve analysis to calculate the value of CBF: initial slope index, ${ }^{32,35,46}$ determined from the slope of the first minute of the clearance curve; stochastic method; ${ }^{21,22,32,46}$ and two-compartmental analysis ${ }^{20,21,46}$ to yield both gray and white matter $\mathrm{CBF}$ values. The initial slope index is most commonly used, whereas the other two analytical methods require an online computer to determine results.

In using the initial slope index, the primary hypothesis is that blood flow in the cerebral grey matter dominates the first part of the initial fall period of the clearance

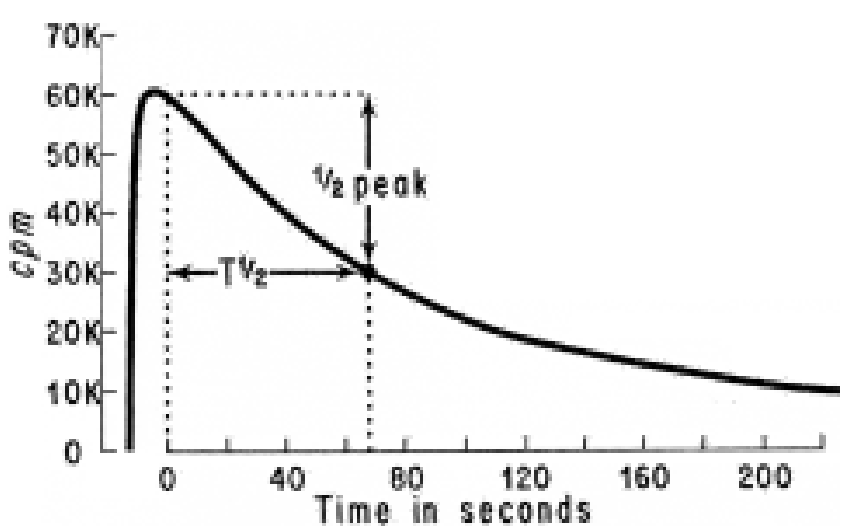

Fig. 2. Graph showing CBF curve following intraarterial injection of ${ }^{133} \mathrm{Xe}$ into the internal CA. Cerebral blood flow in milliliters per $100 \mathrm{~g}$ per minute is calculated by dividing 3600 by the one-half peak value in seconds - in this example $55.5 \mathrm{ml} / 100 \mathrm{~g} / \mathrm{min} . \mathrm{cpm}=$ counts per minute. With permission from the Mayo Foundation.

curve. Therefore, the first 1 to 2 minutes of the clearance curve can be regarded as a monoexponential function. The equation for the initial slope can be described as:

regional $\mathrm{CBF}(\mathrm{ml} / \mathrm{g} / \mathrm{min})=\lambda \times 2.3 \times \mathrm{F}($ initial $)$

where $\lambda$ is the tissue to blood partition coefficient for ${ }^{133} \mathrm{Xe}$ in gray matter, 2.3 is the factor for converting common to natural logarithms, and $\mathrm{F}$ (initial) is the numerical value of the slope in semilog (base 10) system. The value for the partition coefficient used is 0.87 because it represents the first descending part of the clearance curve relating to gray matter. ${ }^{21,32,35,46}$ The initial slope analysis does not take into consideration differences in the amount of gray matter being monitored. If a single detector is used and is always placed in the same anatomical location, then the potential for this error is greatly diminished. The advantage of this method is that measurements can be made serially with short wait times, provided that the isotope is adequately cleared from the brain. Because of the simplicity of the equation, a hand-held calculator can be used to compute the blood flow values quickly. ${ }^{2}$

A primary limitation of $\mathrm{CBF}$ measurement in ${ }^{133} \mathrm{Xe}$ studies is the "look-through" phenomenon. ${ }^{14,18}$ This is the failure to indicate areas of low- or no-flow regions because the detector can see only areas of perfused tissue. In other words, the detector sees the under- and/or overlying tissue and also tissue peripheral to the area in the field of view. A second limitation is that performing fast serial measurements introduces error. The time interval between $\mathrm{CBF}$ measurements at 5 minutes and 10 minutes will results in overestimation of CBF by $10 \%$ and $5 \%$, respectively. ${ }^{24}$ Therefore, a waiting period is recommended between measurements to minimize errors due to a greater than normal background. A third limitation is Compton scattering, ${ }^{36}$ which may introduce considerable error in the determination of the volume and severity of focal ischemia. Compton-scattered photons can be minimized by setting the lower level of the pulse-height analyzer to 75 keV. ${ }^{35}$

\section{Ultrasonic Perivascular Flow Probe}

An ultrasound-based device historically used in vascular and cardiac surgery, the ultrasonic perivascular flow 
probe, has recently been used in cerebrovascular procedures-typically in aneurysm surgery. ${ }^{10,11}$ In this probe a small pencillike device with a semicircular tip uses ultrasound transit time to measure blood flow. The tip is positioned such that the vessel of interest is contained within the diameter of the semicircle. A quantitative measure of $\mathrm{CBF}$ is obtained, and the accuracy of the technique has been convincingly validated. . $^{19,28,47}$ With this device, blood flow in individual cerebral vessels can be quantified immediately following placement of an aneurysm clip to verify the sufficiency of flow in the parent artery or nearby perforating arteries. ${ }^{9}$ The technique is fast, easy to perform, and can be repeated after multiple clip applications. We have found it extremely useful in the surgical repair of complex aneurysms, alone or as a quantitative adjunct to intraoperative angiography. ${ }^{15}$

\section{Thermal Diffusion Flowmetry}

In 1933 Gibbs (unpublished data) first described the use of the thermal diffusion technique to measure CBF. He used a heated thermocoupler to measure flow though the internal jugular vein. However, by nature of its design, it could accurately reflect relative changes but not absolute values. Brawley ${ }^{6}$ furthered the technique by incorporating a Peltier stack to improve the stability of the recording probe, thereby enabling measurement of CBF over extended periods of time as well as measurement quantitation. Carter, et al., ${ }^{7}$ eliminated the Peltier stack to miniaturize the recording probe so that it could be more easily used postoperatively in a wide variety of cases.

The probe has two gold plates in a thin 3-mm Silastic sheath, one heated and one nonheated. The temperature difference between these plates is monitored constantly by computer, and the resultant difference is converted to a $\mathrm{CBF}$ value in milliliters per $100 \mathrm{~g}$ per minute. The following is the mathematical formula derived to quantify cerebral flow by thermal diffusion:

$\mathrm{CBF}=\mathrm{K}(1 / \mathrm{V}-1 / \mathrm{Vo})$,

where $\mathrm{CBF}$ is the cortical blood flow in milliliters per 100 $\mathrm{g}$ per minute, $\mathrm{K}$ is the conductivity constant of brain tissue, $\mathrm{V}$ is the voltage difference between the two plates, and Vo is the voltage difference between the two plates at zero flow. The depth range of the measurement of CBF by thermal diffusion in brain tissue is approximately 1.5 $\mathrm{mm} .{ }^{16}$ Care must be taken not to place the probe on any major surface vessel. The probe must be in contact with the tissue surface to provide valid temperature measurements. Because the placement of the probe must be visually inspected in relation to the cortex, it may be difficult to install the probe at a bedside setting.

The measurement of CBF by thermal diffusion has been used postoperatively to monitor patients who have undergone aneurysm clipping or resection of cerebral arteriovenous malformations. ${ }^{8}$ It has also been used to monitor patients with temporal lobe epilepsy or after severe head injury. ${ }^{8,41}$ The advantage of measuring $\mathrm{CBF}$ by thermal diffusion is that real-time continuous monitor of $\mathrm{CBF}$ is possible. The disadvantage is that this technique measures small volumes of tissue and results in possible inaccuracies because of the heterogeneity of blood flow distribution.

\section{CONCLUSIONS}

Continued refinement of techniques for the monitoring of CBF has led to an increasing number of clinical applications. Despite these advances, no existing CBF monitoring technique is without certain limitations. Understanding specific advantages and drawbacks of available techniques allows for selection of the most appropriate intraoperative monitoring technique for each patient.

\section{References}

1. Ackerstaff RGA, Moons KGM, van de Vlasakker CJW, et al: Association of intraoperative transcranial doppler monitoring variables with stroke from carotid endarterectomy. Stroke 31: 1817-1823, 2000

2. Anderson RE: Cerebral blood flow xenon-133. Neurosurg Clin North Am 7:703-708, 1996

3. Batjer HH, Frankfurt AI, Purdy PD, et al: Use of etomidate, temporary arterial occlusion, and intraoperative angiography in surgical treatment of large and giant aneurysms. J Neurosurg 68:234-240, 1988

4. Boysen G: Cerebral blood flow measurement as a safeguard during carotid endarterectomy. Stroke 2:1-10, 1971

5. Boysen G, Ladegaard-Pederson HJ, Henriksen H, et al: The effects of $\mathrm{PaCO}_{2}$ on regional $\mathrm{CBF}$ and internal carotid arterial pressure during carotid clamping. Anesthesiology 35:286-300, 1971

6. Brawley BW: The pathophysiology of intracerebral steal following carbon dioxide inhalation: an experimental study. Scand J Clin Lab Invest Suppl 102:XIII:B, 1968

7. Carter LP, Weinland ME, Oommen KJ: Cerebral blood flow monitoring (CBF) in intensive care by thermal diffusion. Acta Neurochir Suppl 59:43-46, 1993

8. Carter LP, White WL, Atkinson JR: Regional cortical blood flow at craniotomy. Neurosurgery 3:223-229, 1978

9. Charbel FT, Gonzales-Portillo G, Hoffman WE, et al: Quantitative assesment of vessel flow integrity for aneurysm surgery. Technical note. J Neurosurg 91:1050-1054, 1999

10. Charbel FT, Hoffman WE, Misra M, et al: Role of a perivascular ultrasonic micro-flow probe in aneurysm surgery. Neurol Med Chir 38 (Suppl):35-38, 1998

11. Charbel FT, Hoffman WE, Misra M, et al: Ultrasonic perivascular flow probe: technique and application in neurosurgery. Neurol Res 20:439-442, 1998

12. Chiappa KH, Burke SR, Young RR: Results of electroencephalographic monitoring during 367 carotid endarterectomies. Use of a dedicated minicomputer. Stroke 10:381-388, 1979

13. Dalman JE, Beenakkers ICM, Moll FL, et al: Transcranial doppler monitoring during carotid endarterectomy helps to identify patients at risk of postoperative hyperperfusion. Eur J Vasc Endovasc Surg 18:222-227, 1999

14. Donley RF, Sundt TM, Anderson RE, et al: Blood flow measurements and the "look through" artifact in focal cerebral ischemia. Stroke 6:121-131, 1975

15. Friedman JA, Meyer FB, Nichols DA, et al: Surgical repair of endovascularly untreatable transitional carotid-cavernous aneurysms. J Neurosurg 92:552, 2000 (Abstract)

16. Golenhofer K, Hensel H, Hilderbrant G: Durchblutungsmessungen mit Warmeleitelementen in Forschung und Klinik. Stuttgart: Thieme, 1963

17. Halsey JH Jr: Risks and benefits of shunting in carotid endarterectomy. The International Transcranial Doppler Collaborators. Stroke 23:1583-1587, 1992

18. Hanson EJ, Anderson RE, Sundt TM Jr: Comparison of ${ }^{85} \mathrm{kryp}-$ ton and ${ }^{133}$ xenon cerebral blood flow measurements before, during, and following focal, incomplete ischemia in the squirrel monkey. Circ Res 36:18-26, 1975 
19. Hartman JD, Olszanske DA, Hullinger TG, et al: In vivo validation of a transit-time ultrasonic volume flow meter. J Pharmacol Toxicol Methods 31:153-160, 1994

20. Hoedt-Rasmussen K: Regional cerebral blood flow. The intraarterial injection method. Acta Neurol Scand Suppl 43:1-81, 1967

21. Hoedt-Rasmussen K, Sveinsdottir E, Lassen NA: Regional cerebral blood flow in man determined by intra-arterial injection of radioactive inert gas. Circ Res 18:237-247, 1966

22. Horsch S, De Vleeschauwer PH, Ktenidis K: Intraoperative assessment of cerebral ischemia during carotid surgery. J Cardiovasc Surg 31:599, 1990

23. Jansen C, Ramos LM, van Heesewijk JP, et al: Impact of microembolism and hemodynamic changes in the brain during carotid endarterectomy. Stroke 25:992-997, 1994

24. Kanno I, Uemura K: Some experimental errors in calculation of regional cerebral blood flow from the intracarotid xenon-133 clearance curve: a quantitative evaluation employing a digital model. Stroke 6:370-375, 1975

25. Lam AM, Newell DW: Intraoperative use of transcranial doppler ultrasonography. Neurosurg Clin North Am 7:709-722, 1996

26. Langfitt TW, Obrist WD: Cerebral blood flow, in Wilkins RH, Rengachary SS (eds): Neurosurgery. New York: McGrawHill, 1985, Vol 1, pp 1167-1173

27. Levi CR, O'Malley HM, Fell G, et al: Transcranial doppler detected cerebral microembolism following carotid endarterectomy: high microembolic signal loads predict postoperative cerebral ischemia. Brain 120:621-629, 1997

28. Lundell A, Bergqvist D, Maattsson E, et al: Volume blood flow measurements with a transit time flowmeter: an in vivo and in vitro variability and validation study. Clin Physiol 13: 547-557, 1993

29. McGrail KM: Intraoperative use of electroencephalography as an assessment of cerebral blood flow. Neurosurg Clin North Am 7:685-692, 1996

30. Nichols DA, Meyer FB, Piepgras DG: Endovascular treatment of intracranial aneurysms. Mayo Clin Proc 69:272-285, 1994

31. Ojemann RG, Crowell RM, Robertson GH, et al: Surgical treatment of extracranial carotid occlusive disease. Clin Neurosurg 22:214-263, 1975

32. Olesen J, Paulson OB, Lassen NA: Regional cerebral blood flow in man determined by the initial slope of the clearance of intra-arterially injected ${ }^{133}$ Xe. Stroke 2:519-540, 1971

33. Origitano TC, Schwartz K, Anderson D, et al: Optimal clip application and intraoperative angiography for intensive care aneurysms. Surg Neurol 51:117-128, 1999

34. Papavasiliou AK, Magnadottir HB, Gonda T, et al: Clinical outcomes after carotid endarterectomy: comparison of the use of regional and general anesthetics. J Neurosurg 92:291-296, 2000

35. Paulson OB, Cronqvist S, Risberg J, et al: Regional cerebral blood flow: comparison of 8-detector and 16-detector instrumentation. J Nucl Med 10:164-173, 1968
36. Potchen EJ, Davis DO, Wharton T, et al: Regional cerebral blood flow in man. I. A study of the xenon 133 washout method. Arch Neurol 20:378-383, 1969

37. Ravussin P, de Tribolet N: Total intravenous anesthesia with protocol for bust suppression in cerebral aneurysm surgery: preliminary report of 42 patients. Neurosurgery 32:236-240, 1993

38. Redekop G, Ferguson G: Correlation of contralateral stenosis and intraoperative electroencephalogram change with risk of stroke during carotid endarterectomy. Neurosurgery 30: 191-194, 1992

39. Selman WR, Spetzler RF, Roessmann UR, et al: Barbiturateinduced coma therapy for focal cerebral ischemia. Effect of temporary and permanent MCA occlusion. J Neurosurg 55: 220-226, 1981

40. Sharbrough FW, Messick JM Jr, Sundt TM Jr: Correlation of continuous electroencephalograms with cerebral blood flow measurements during carotid endarterectomy. Stroke 4: 674-683, 1973

41. Sioutos PJ, Orozco JA, Carter LP, et al: Continuous regional cerebral cortical blood flow monitoring in head-injured patients. Neurosurgery 36:943-950, 1995

42. Spencer MP: Transcranial doppler monitoring and causes of stroke from carotid endarterectomy. Stroke 28:685-691, 1997

43. Sundt TM Jr, Sharbrough FW, Anderson RE, et al: Cerebral blood flow measurements and electroencephalograms during carotid endarterectomy. J Neurosurg 41:310-320, 1974

44. Sundt TM Jr, Sharbrough FW, Piepgras DG, et al: Correlation of cerebral blood flow and electroencephalographic changes during carotid endarterectomy: with results of surgery and hemodynamics of cerebral ischemia.Mayo Clin Proc 56: 533-543, 1981

45. Tang G, Cawley CM, Barrow DL: Prospective use of intraoperative angiography in 520 consecutive cerebral aneurysms. Neurosurgery 47:499, 2000 (Abstract)

46. Waltz AG, Wanek AR, Anderson RE: Comparison of analytic methods for calculation of cerebral blood flow after intracarotid injection of Xe-133. J Nucl Med 13:66-72, 1972

47. Wen C, Li M, Whitworth JA: Validation of transonic small animal flowmeter for measurement of cardiac output and regional blood flow in the rat. J Cardiovasc Pharmacol 4:482-486, 1996

48. Zampella E, Morawetz RB, McDowell HA, et al: The importance of cerebral ischemia during carotid endarterectomy. Neurosurgery 29:727-731, 1991

Manuscript received September 15, 2000.

Accepted in final form October 12, 2000.

Address reprint requests to: Jonathan A. Friedman, M.D., Department of Neurological Surgery, Joseph 1-229, Saint Mary's Hospital, 1216 Second Street SW, Rochester, Minnesota 55905. email: friedman.jonathan@mayo.edu. 